\title{
Strategic Directions for Invasive Species Research at the Upper Midwest Environmental Sciences Center
}

Considerable increases in the rates of invasion by aquatic species and a lack of viable control options present decision makers with few management options. To meet the need for a more comprehensive program addressing the establishment, spread, and effects of aquatic invasive species in the Midwest, a number of scientists at the U.S. Geological Survey Upper Midwest Environmental Sciences Center (UMESC) are refocusing their research efforts on aquatic invasive species based on UMESC personnel, facility assets, and resource management needs.

\section{Identifying Resource Management Needs}

Research directions for UMESC on aquatic invasive species were identified in a strategic plan reviewed by resource managers and other interested parties at a 2004 UMESCsponsored workshop. Top research priorities identified at the workshop include conducting risk assessments to prevent new introductions, developing tools to respond rapidly to new introductions, assessing the effects of new invaders, and developing new control methods.

\section{Changing Societal Needs}

The UMESC has a proud history in invasive species research focused primarily on developing tools for chemical control of sea lamprey and other nuisance fishes such as common carp. Although UMESC scientists have established a considerable reputation for successful chemical control of aquatic species, we have a goal of broading our research capabilities to meet the changing needs of society and resource management. More specifically, we intend to maintain our unique capabilities in chemical control methods and regulatory affairs while expanding and diversifying research in aquatic invasive species.

\section{Invasive Species Research Directions}

Over the next 5 years, we will direct invasive species research at the UMESC on the following activities:

\section{$\checkmark$ Preventing the Introduction of Aquatic Invasive} Species: Developing tools to aid managers in preventing the introduction of aquatic invasive species in the United States.

$\checkmark$ Early Detection, Rapid Response, and Spread of Aquatic Invasive Species: Use current expertise at the UMESC to provide science support for managers to eradicate newly reported aquatic invasive species and to predict their potential spread in the Great Lakes and Upper Mississippi River basins.

\section{$\checkmark$ Science Support for Monitoring Aquatic} Invasive Species: Improve and refine methods used by managers to monitor expanding populations of aquatic invasive species in the Upper Mississippi River System

$\checkmark$ Ecology and Effects of Aquatic Invasive Species: Study the ecology of and identify and quantify the effects of harmful aquatic invasive species on native ecosystems and their components in the Great Lakes and Upper Mississippi River basins

$\checkmark$ Control and Management of Aquatic Invasive Species: Work with managers to develop, improve, and implement an integrated approach (physical, chemical, and biological control methods) for controlling aquatic invasive species to allow restoration and management of native species and ecosystem function 
Interest is growing in predicting the identity, distribution, and effects of potential aquatic invasive species, and UMESC has capabilities in these areas. For example, we have developed a risk assessment for bighead and silver carp and have completed a major effort with the Bureau of Reclamation to examine the use of taxon-specific chemicals and integrated control of invasive fishes in the Southwest. Also, UMESC scientists will continue to provide leadership by serving on the Asian Carp Working Group of the Aquatic Nuisance Species (ANS) Task Force, Risk Assessment Advisory Panel of the National Invasive Species Council, and the Mississippi River Basin Panel on ANS, as well as to address issues related to other nuisance aquatic invasives such as the snakehead.

\section{Aquatic Invasive Species Issues in Proximity}

The UMESC is located on the Mississippi River and is close to the Great Lakes, both highly invaded ecosystems that have undergone negative ecological and economical changes because of invasive species. More than 170 aquatic species have arrived through a variety of biological and physical pathways to become established in these ecosystems. Research on invasive species at the UMESC will focus on preventing further introductions, examining early detection and monitoring methods, determining the effects of established invaders, and the management and control of invasive species in this region.

\section{Assets and Capabilities for Research on Aquatic Invasive Species}

Aquatic invasive species research capabilities at UMESC include:

New containment and experimental complex for aquatic invasive species with recirculating and flowthrough capabilities

$\square$ Unique onsite facilities, including laboratory workspace and outdoor mesocosms and ponds

$\square$ Extensive experience in monitoring aquatic invasive species

$\square$ Expertise in chemical and integrated control of aquatic species

Capabilities in predicting the identity of potential invading species and determining the effects of invading species

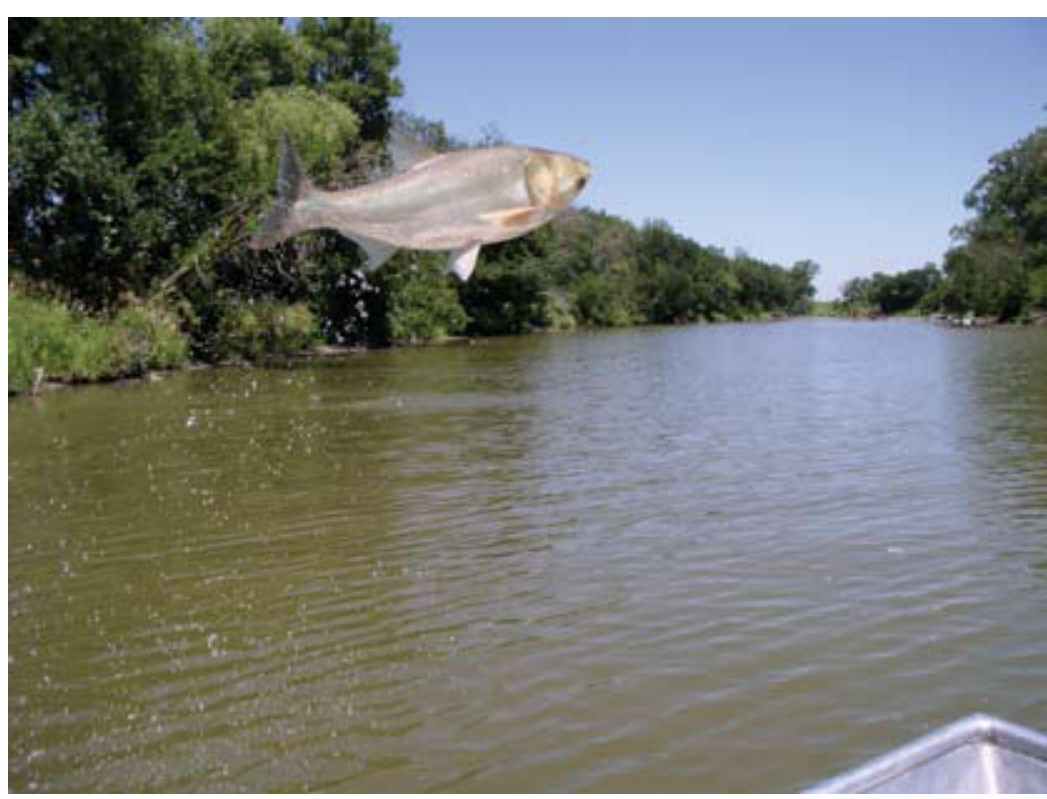

Silver carp have been found in the Upper Mississippi River basin since 1983. They pose danger to boaters and anglers because they respond to boat motor vibrations by leaping several feet out of the water (photograph: R. Nelson).

$\square$ Expertise with historic and ongoing ecological studies in aquatic ecosystems

Strong quantitative focus and strengths in geospatial applications and risk assessments

$\square$ Nationally recognized, innovative decision support systems

\section{Dedicated Research Staff}

Terrance Hubert, Ph.D. Chemist: Pheromones, analytical chemistry, chemical control, integrated pest management, regulatory affairs

Mark P. Gaikowski, M.A. Research Physiologist: Toxicity studies, environmental assessments, delivery technologies

Jon Amberg, Ph.D. Research Fisheries Biologist: Fish metabolism and physiology, PCR analysis and gene expression, xenobiotic metabolism

Michael Boogaard, M.S. Biologist: Toxicity studies, chemical control, rapid response and integrated pest management of aquatic invasive species

Jane Rivera, B.S. Biologist: Regulatory affairs 